\title{
Hydrolysis and Condensation in Systems of Silicon Alkoxide and Hydrated Calcium and Nickel Nitrate in Alcohols as Followed by Means of Fourier-Transform Infrared Spectroscopy
}

\author{
Merete H. Selle ${ }^{a}$, Franka Fredriksen ${ }^{a}$, Johan Sjöblom ${ }^{a}$, Alfred Christy ${ }^{a}$ and Stig E. Friberg ${ }^{b}$ \\ ${ }^{a}$ Department of Chemistry, University of Bergen, Allégaten 41, N-5007 Bergen, Norway and ${ }^{\mathrm{b}}$ Center for Advanced Materials \\ Processing, Clarkson University, Potsdam, NY 13699-5814, USA
}

\begin{abstract}
Selle, M. H., Fredriksen, F., Sjöblom, J., Christy, A. and Friberg, S. E., 1996. Hydrolysis and Condensation in Systems of Silicon Alkoxide and Hydrated Calcium and Nickel Nitrate in Alcohols as Followed by Means of Fourier-Transform Infrared Spectroscopy. - Acta Chem. Scand. 50: 12-17 (O Acta Chemica Scandinavica 1996.

Hydrolysis and condensation reactions were investigated between tetramethy orthosilicate (TMOS) or tetraethyl orthosilicate (TEOS) and calcium nitrate hydrate $\left(\mathrm{Ca}\left(\mathrm{NO}_{3}\right)_{2} \cdot 4 \mathrm{H}_{2} \mathrm{O}\right)$ or nickel nitrate hydrate $\left(\mathrm{Ni}\left(\mathrm{NO}_{3}\right)_{2} \cdot 6 \mathrm{H}_{2} \mathrm{O}\right)$ in alcohols, methanol or ethanol. The reactions have been followed by means of FTIR spectroscopy. It was found that the reaction between hydration water and TMOS (TEOS) was of second order. It was found that the rate of hydrolysis increased with increasing amount of hydration water. In the $\mathrm{Ni}$ system all reactions proceeded more readily. Comparison with literature values for the hydrolysis rate reveal that dissolution of hydration water into the alcohol medium can play a role at the highest hydration water contents.
\end{abstract}

The sol-gel method includes hydrolysis and condensation of a metal alkoxide, often tetramethyl orthosilicate (TMOS) or tetraethyl orthosilicate (TEOS), in an alcohol solution. The process can be described by the following equations ${ }^{1}$

Hydrolysis:

$\equiv \mathrm{Si}-\mathrm{OR}+\mathrm{H}_{2} \mathrm{O} \rightleftharpoons \equiv \mathrm{Si}-\mathrm{OH}+\mathrm{ROH}$

Water condensation:

$\equiv \mathrm{Si}-\mathrm{OH}+\equiv \mathrm{Si}-\mathrm{OH} \rightleftharpoons \leftrightarrow \equiv \mathrm{Si}-\mathrm{O}-\mathrm{Si} \equiv+\mathrm{H}_{2} \mathrm{O}$

Alcohol condensation:

$\equiv \mathrm{Si}-\mathrm{OH}+\equiv \mathrm{Si}-\mathrm{OR} \rightleftharpoons \leftrightarrow \equiv \mathrm{Si}-\mathrm{O}-\mathrm{Si} \equiv+\mathrm{ROH}$

where $\mathrm{R}$ is an alkyl group, $\mathrm{C}_{x} \mathrm{H}_{2 x+1}$. The product of the process depends highly on the $\mathrm{pH}$ of the solution. At low $\mathrm{pH}$ hydrolysis, reaction (1), is faster than the condensation, reactions (2) and (3). The result is the formation of an irregular polymer which transforms the solution into a gel. ${ }^{1}$ At high $\mathrm{pH}$ the opposite is true, and hence particles are formed, and at low $\mathrm{pH}$ gels are formed. In the present study only reactions at low $\mathrm{pH}$ are investigated.
In this study two hydrated metal salts, $\mathrm{Ca}\left(\mathrm{NO}_{3}\right)_{2} \cdot 4 \mathrm{H}_{2} \mathrm{O}$ and $\mathrm{Ni}\left(\mathrm{NO}_{3}\right)_{2} \cdot 6 \mathrm{H}_{2} \mathrm{O}$, are dissolved into the alcohols, methanol or ethanol. By adding a hydrated metal salt to the solution no extra water has to be introduced when the sol-gel process is carried out. Systems consisting of alcohol, metal salts and alkoxides are of interest because in this way colloidal metal can be incorporated into the gel matrix. These gels are conducting, and they can find applications within electronics and optics. $^{2}$

There exist several reports on reaction rate constants for the hydrolysis of silicon alkoxides, but until recently the results did not show acceptable consistency. ${ }^{3-5} \mathrm{Ae}-$ lion et al. ${ }^{3}$ investigated the hydrolysis of tetraethyl orthosilicate and found that an acid-catalyzed hydrolysis is of second order with respect to both water and alkoxide. It was found that the overall hydrolysis rate constant was in the range $>0.3 \mathrm{~L}(\mathrm{~mol} \mathrm{~h})^{-1}$. Assink and $\mathrm{Kay}^{4}$ developed a model in which they assumed equal and independent reactivity of the functional groups of the alkoxide (TMOS), and the reversibility of the reactions was neglected. The authors found a linear decrease in rates for the four consecutive monomer hydrolysis reactions owing to a decrease in the number of OR groups available for hydrolysis. The hydrolysis rate constants were calculated to be $>12 \mathrm{~L}(\mathrm{~mol} \mathrm{~h})^{-1}$. Pouxviel et al. ${ }^{5}$ and Yang et al. ${ }^{6}$ 
observed experimentally the opposite trend: they found that the hydrolysis rate constant increased for each consecutive monomer reaction. They found the hydrolysis rate constants to be $>0.8 \mathrm{~h}^{-1}$ and $\left.>0.8 \mathrm{~L} \mathrm{(mol} \mathrm{h}\right)^{-1}$, respectively. The difference in the rate constant units is due to the assumption of a first-order reaction. ${ }^{6}$ The difference between the results by Assink and Kay, ${ }^{4}$ Pouxviel $^{5}$ and $\mathrm{Yang}^{6}$ have been clarified by the recent publication by McCormick et al. $^{7}$ revealing the opposite influence on the reaction rate by kinetic and thermodynamic factors.

Recently, investigations into the sol-gel process have been extended to the reactions between alkoxysilanes and metal salt hydrates, ${ }^{8,9}$ utilizing the high solubility of these compounds in alcohols. ${ }^{10}$ Such reactions are of interest because they offer an avenue to conducting gels with applications within electronics and optics. ${ }^{2}$ We found these reactions of interest, and in this study we report on the reactions between two hydrated metal salts, $\mathrm{Ca}\left(\mathrm{NO}_{3}\right)_{2} \cdot 4 \mathrm{H}_{2} \mathrm{O}$ and $\mathrm{Ni}\left(\mathrm{NO}_{3}\right)_{2} \cdot 6 \mathrm{H}_{2} \mathrm{O}$, and alkoxysilanes TMOS and TEOS in methanol and ethanol. The reaction was followed by means of Fourier-transformation infrared (FTIR) spectroscopy.

\section{Experimental}

Materials. Calcium nitrate tetrahydrate $(>99 \%)$ and methanol ( $>99.8 \%$ ) were both from Merck (Darmstadt, Germany). Nickel nitrate hexahydrate ( $>99 \%$ ) was from J. T. Baker, and the dehydrated ethanol was from A/S Vinmonopolet. Tetramethyl orthosilicate $(>98 \%)$ and tetraethyl orthosilicate $(>98 \%)$ were both from Fluka.
The Hydranal Composite 5 was from Riedel-de Häen. All chemicals were used without further purification.

Karl-Fischer titration. The exact amount of water in $\mathrm{Ca}\left(\mathrm{NO}_{3}\right)_{2} \cdot 4 \mathrm{H}_{2} \mathrm{O}$ and $\mathrm{Ni}\left(\mathrm{NO}_{3}\right)_{2} \cdot 6 \mathrm{H}_{2} \mathrm{O}$ was determined by Karl-Fischer titration. A small, exact amount of the hydrated metal salt was dissolved in prehydrated methanol. The solution was titrated with Hydranal Composite 5 until the endpoint was obtained. The analysis was carried out with a Mettler Karl-Fischer titrator DL18.

Sample preparation. $45 \%$ by weight of $\mathrm{Ca}\left(\mathrm{NO}_{3}\right)_{2} \cdot 4 \mathrm{H}_{2} \mathrm{O}$ and $\mathrm{Ni}\left(\mathrm{NO}_{3}\right)_{2} \cdot 6 \mathrm{H}_{2} \mathrm{O}$ was dissolved into the two waterfree alcohols, and TMOS or TEOS was added to the samples. Different ratios of hydration water to alkoxide $(R)$ were chosen $(2 / 1,8 / 3$ and $4 / 1$, and in some cases $8 / 1$ ). The samples were subsequently mixed in an ultrasound bath.

FTIR spectra. The spectra were measured using a PerkinElmer 1720FX FTIR spectrometer equipped with a DTGS (deuterated triglycine sulfate) detector and a Spectra-Tech macro-circle cell. In all cases a total of 20 scans were made at resolution of $4 \mathrm{~cm}^{-1}$ in the range $4000-600 \mathrm{~cm}^{-1}$. The background spectrum was measured with an empty circle cell. Samples were measured soon after transparency was achieved as a function of time. The spectra in reflectance $(R)$ format were transformed into $\log (1 / R)$ format, and areas under relevant peaks were integrated $\left[1720-1610 \mathrm{~cm}^{-1}\left(\mathrm{H}_{2} \mathrm{O}\right.\right.$ scissoring), $1240-1150 \mathrm{~cm}^{-1}\left(\mathrm{Si}-\mathrm{OCH}_{3}\right.$ stretch $), 1220-$ $1140 \mathrm{~cm}^{-1}\left(\mathrm{Si}-\mathrm{OCH}_{2} \mathrm{CH}_{3}\right.$ stretch) and $980-880 \mathrm{~cm}^{-1}$ ( $\mathrm{Si}-\mathrm{OH}$ stretch, TMOS)], Fig. 1.

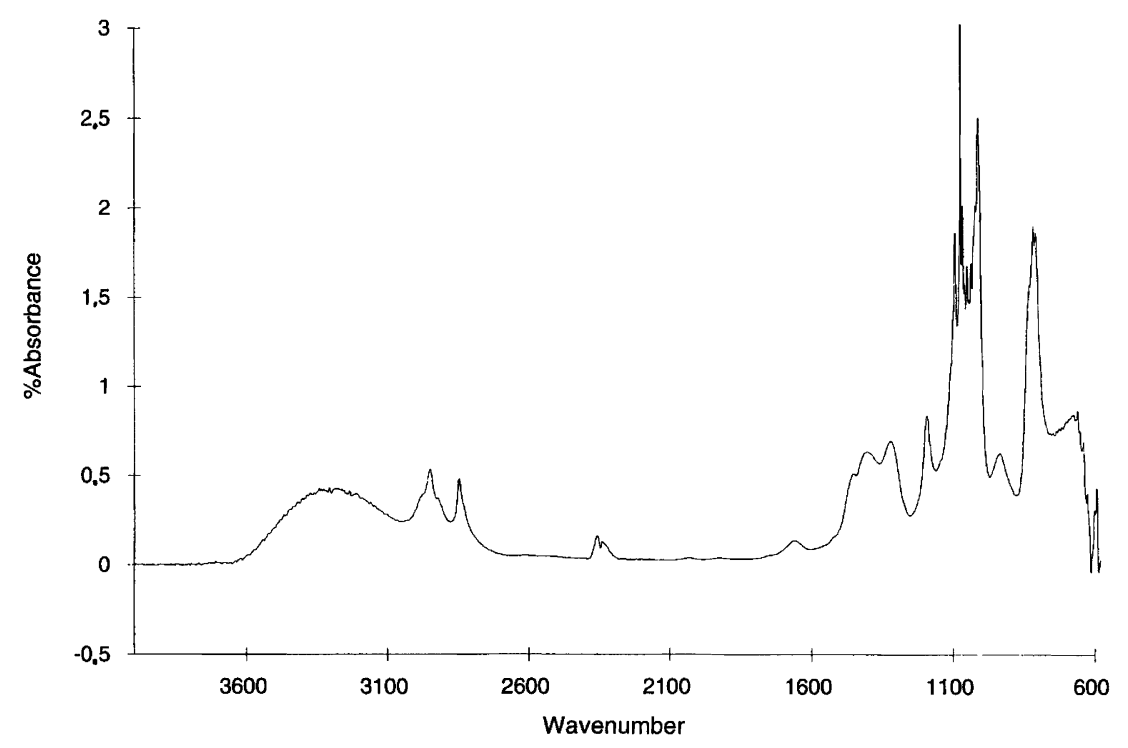

Fig. 1. FTIR spectrum of $45 \mathrm{wt} \% \mathrm{Ni}\left(\mathrm{NO}_{3}\right)_{2} \cdot 6 \mathrm{H}_{2} \mathrm{O}$ in methanol with TMOS. The molar ratio between hydration water and TMOS is $2 / 1$. 


\section{Results}

From the Karl-Fischer titrations it was found that $\mathrm{Ca}\left(\mathrm{NO}_{3}\right)_{2} \cdot 4 \mathrm{H}_{2} \mathrm{O}$ contained 31.40 wt. $\%$ water and $\mathrm{Ni}\left(\mathrm{NO}_{3}\right)_{2} \cdot 6 \mathrm{H}_{2} \mathrm{O}$ contained 37.46 wt. $\%$ water. This is equivalent to $\mathrm{Ca}\left(\mathrm{NO}_{3}\right)_{2} \cdot 4.12 \mathrm{H}_{2} \mathrm{O}$ and $\mathrm{Ni}\left(\mathrm{NO}_{3}\right)_{2} \cdot 6.04$
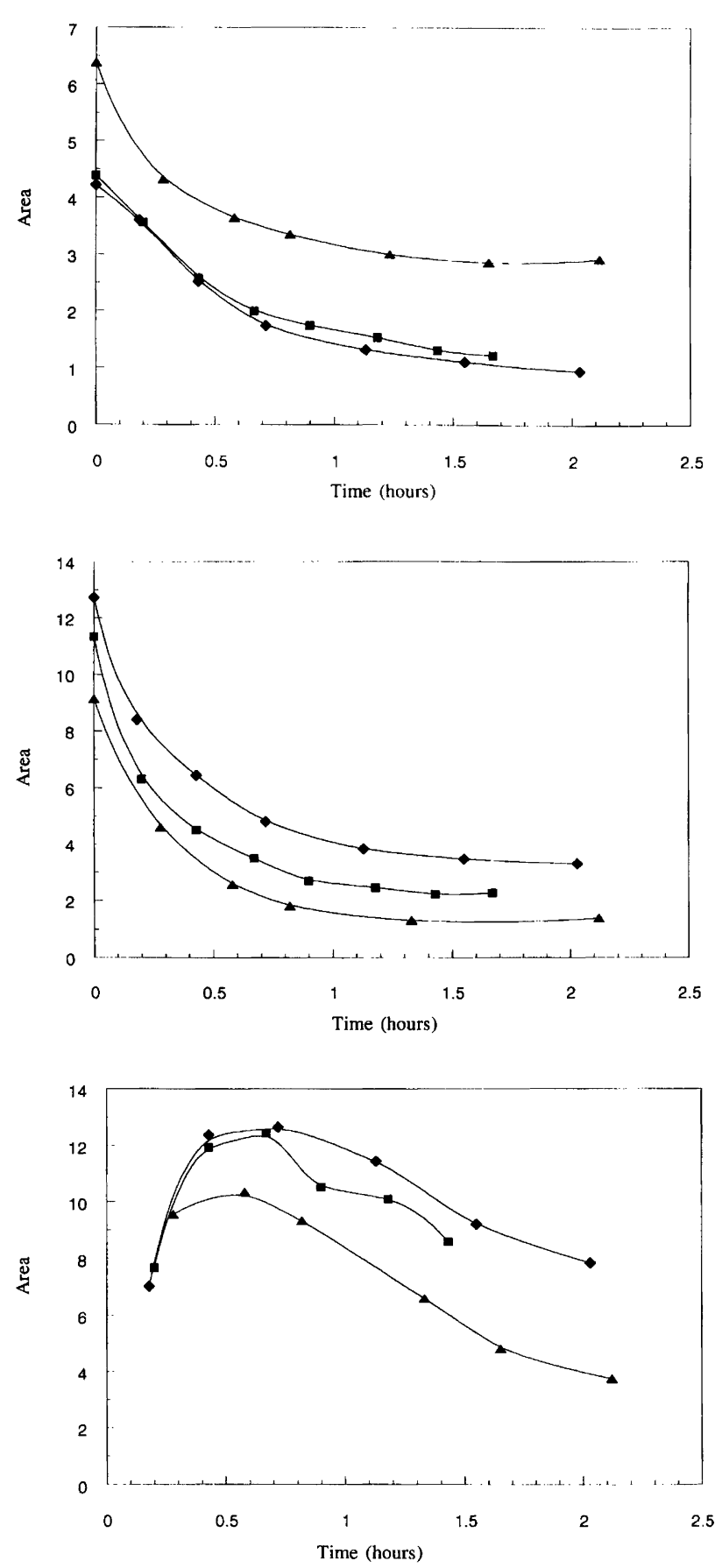

Fig. 2. Changes in different areas in the IR spectrum as a function of time. The sample consist of 45 wt. \% $\mathrm{Ni}\left(\mathrm{NO}_{3}\right)_{2} \cdot 6 \mathrm{H}_{2} \mathrm{O}$ in methanol with TMOS. The molar ratios between hydration water and TMOS are:,$(2 / 1) ; \square,(8 / 3)$ and $\boldsymbol{\Delta}$, (4/1). (a) $\mathrm{H}_{2} \mathrm{O}$, (b) $\mathrm{Si}-\mathrm{OCH}_{3}$ and (c) $\mathrm{Si}-\mathrm{OH}$.
$\mathrm{H}_{2} \mathrm{O}$. The water amounts found by Karl-Fischer titrations are used in all calculations in this study.

It is generally seen that peak areas of both water and $\equiv \mathrm{Si}-\mathrm{OR}$ decrease as a function of time (Figs. 2a and 2b). Using TMOS, a peak assigned to $\equiv \mathrm{Si}-\mathrm{OH}$ can be observed at $980-880 \mathrm{~cm}^{-1}$. The area of the peak
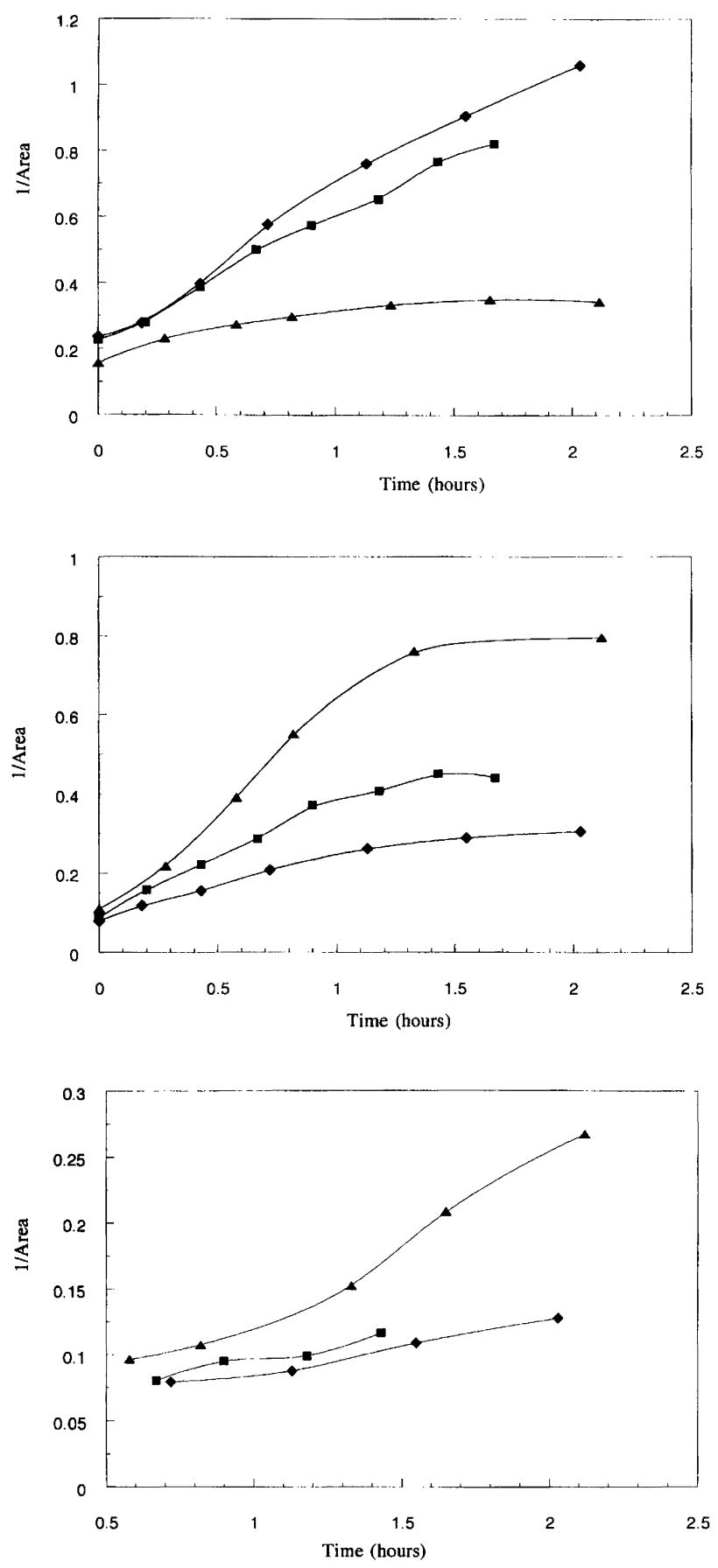

Fig. 3. Inverse area values (from Fig. 2) as a function of time. The linearization of the data in Fig. 2 is according to a second-order reaction. The molar ratio between hydration water and TMOS are: $(2 / 1) ; \square,(8 / 3)$ and $\boldsymbol{\Delta},(4 / 1)$. (a) $\mathrm{H}_{2} \mathrm{O}$, (b) $\mathrm{Si}-\mathrm{OCH}_{3}$ and (c) $\mathrm{Si}-\mathrm{OH}$. 
Table 1. Rate constants for the reactions between TMOS and hydrated metal salts in an alcohol solution. ${ }^{a}$

\begin{tabular}{|c|c|c|c|c|c|c|c|c|}
\hline \multirow[b]{3}{*}{ TMOS in } & \multicolumn{8}{|c|}{$\mathrm{H}_{2} \mathrm{O} / \mathrm{TMOS}(R)$} \\
\hline & \multicolumn{2}{|l|}{$2 / 1$} & \multicolumn{2}{|l|}{$8 / 3$} & \multicolumn{2}{|l|}{$4 / 1$} & \multicolumn{2}{|l|}{$8 / 1$} \\
\hline & $k^{\prime}$ & $k^{\prime \prime}$ & $k^{\prime}$ & $k^{\prime \prime}$ & $k^{\prime}$ & $k^{\prime \prime}$ & $k^{\prime}$ & $k^{\prime \prime}$ \\
\hline $\mathrm{Ca} / \mathrm{MeOH}$ & 0.053 & 0.036 & 0.110 & 0.024 & 0.234 & 0.021 & 0.672 & 0.007 \\
\hline $\mathrm{Ca} / \mathrm{EtOH}$ & 0.159 & 0.039 & 0.121 & 0.018 & 0.250 & 0.013 & 0.710 & 0.006 \\
\hline $\mathrm{Ni} / \mathrm{MeOH}$ & 0.307 & 0.296 & 0.720 & 0.234 & 1.329 & 0.068 & - & - \\
\hline $\mathrm{Ni} / \mathrm{EtOH}$ & 0.493 & 1.019 & 2.553 & 0.568 & 6.439 & - & - & - \\
\hline
\end{tabular}

${ }^{a} k^{\prime}$ is calculated from $\mathrm{Si}-\mathrm{OCH}_{3}$ and $k^{\prime \prime}$ is calculated from $\mathrm{H}_{2} \mathrm{O}$.

increased for approximately $30 \mathrm{~min}$, and then started to decrease as a function of time (Fig. 2c). When TEOS is used, the $\equiv \mathrm{Si}-\mathrm{OH}$ peak is not observed owing to an overlap effect between TEOS and the alcohols.

The data in Figs. $2 \mathrm{a}$ and $2 \mathrm{~b}$ can be linearized by assuming a second-order reaction, Fig. 3 . From these data the reaction rate constants, eqn. (4), can be calculated (Tables 1 and 2). The first rate constant, $k^{\mathrm{I}}$, is calculated from $\mathrm{Si}-\mathrm{OCH}_{3}\left(\mathrm{Si}-\mathrm{OCH}_{2} \mathrm{CH}_{3}\right)$ and reflects the hydrolysis. The second rate constant, $k^{\mathrm{II}}$, is calculated from $\mathrm{H}_{2} \mathrm{O}$, and will therefore be influenced by the formation of water in reaction (2).

It is seen from Tables 1 and 2 that $k^{\mathrm{I}}$ increases with increasing molar ratio between hydration water and alkoxide $(R)$, while $k^{\mathrm{II}}$ decreases. An effect of the different hydrated metal salts is also observed.

\section{Discussion}

The kinetics of the hydrolysis and condensation of the sol-gel process have been investigated by several authors. $^{3-9,11,12}$ Since hydrolysis and condensation occur concurrently, the determination of the single rate constants is a rather cumbersome task. ${ }^{7}$ Schematically a second-order reaction for the condensation can be put forward, ${ }^{11}$ i.e.

$\frac{\mathrm{d}[(\mathrm{SiO}) \mathrm{Si}]}{\mathrm{d} t}=k_{1}[\mathrm{SiOH}]^{2}+k_{2}[\mathrm{SiOH}][\mathrm{SiOR}]$

In eqn. (4) a large value of $k_{1}$ will give a proportionality between $[\mathrm{SiOH}]^{2}$ and the condensation rate. Otherwise there will be a linearity between $[\mathrm{SiOH}][\mathrm{SiOR}]$ and the condensation. Depending on the ratio between the rate of hydrolysis and condensation, or if the hydrolysis is complete, other kinetic expressions for the condensation are derived.

In the present work we have followed the changes in intensity of the peaks at 1720-1610, 1240-1150 (12201140) and 980-880 $\mathrm{cm}^{-1}$ representing $\mathrm{H}_{2} \mathrm{O}$, $\equiv \mathrm{Si}-\mathrm{OR}$ and $\mathrm{Si}-\mathrm{OH}$ in the case of TMOS. The rate of hydrolysis is described by the reduction in the area of the modes $\mathrm{Si}-\mathrm{OCH}_{3}$ and $\mathrm{Si}-\mathrm{OCH}_{2} \mathrm{CH}_{3}$ originating from TMOS and TEOS, respectively. The condensation rate was determined from the decrease in intensity of $\mathrm{Si}-\mathrm{OH}$. The intensity changes of the water mode at $1720-1610 \mathrm{~cm}^{-1}$ reflect both reactions (1) and (2). Water is consumed in the hydrolysis step while it will be released in the condensation. Experimentally we found that the reactions between TMOS (TEOS) and the hydrated metal salts were of second order as monitored by the area losses of the water bending and $\mathrm{Si}-\mathrm{OCH}_{3}\left(\mathrm{Si}-\mathrm{OCH}_{2} \mathrm{CH}_{3}\right)$ stretching modes.

Tables 1 and 2 give the corresponding rate constants as a function of the molar ratio between water and alkoxide. $k^{\mathrm{I}}$ is determined from $\mathrm{Si}-\mathrm{OCH}_{3}\left(\mathrm{Si}-\mathrm{OCH}_{2} \mathrm{CH}_{3}\right)$ and $k^{\mathrm{II}}$ from $\mathrm{H}_{2} \mathrm{O}$. The rate of hydrolysis increases with increasing amount of hydration water to TMOS (TEOS). Obviously less firmly bound hydration waters can easily promote the hydrolysis, while the less accessible ones will retard the hydrolysis reaction. When the hydrolysis is followed by means of two different peaks in the IR spectra it is obvious that $k^{\mathrm{I}}$ is a better measure of the pure hydrolysis, since $k^{\mathrm{II}}$ is influenced by the formation of water

Table 2. Rate constants for the reactions between TEOS and hydrated metal salts in an alcohol solution. ${ }^{a}$

\begin{tabular}{|c|c|c|c|c|c|c|c|c|}
\hline \multirow[b]{3}{*}{ TEOS in } & \multicolumn{8}{|c|}{$\mathrm{H}_{2} \mathrm{O} / \mathrm{TMOS}(R)$} \\
\hline & \multicolumn{2}{|l|}{$2 / 1$} & \multicolumn{2}{|l|}{$8 / 3$} & \multicolumn{2}{|l|}{$4 / 1$} & \multicolumn{2}{|l|}{$8 / 1$} \\
\hline & $k^{\prime}$ & $k^{\prime \prime}$ & $k^{\prime}$ & $k^{\prime \prime}$ & $k^{\prime}$ & $k^{\prime \prime}$ & $k^{\prime}$ & $k^{\prime \prime}$ \\
\hline $\mathrm{Ca} / \mathrm{MeOH}$ & 0.113 & 0.139 & 0.223 & 0.063 & 1.038 & 0.015 & - & - \\
\hline $\mathrm{Ca} / \mathrm{EtOH}$ & 0.047 & 0.071 & 0.078 & 0.034 & 0.289 & 0.030 & 0.722 & 0.010 \\
\hline $\mathrm{Ni} / \mathrm{MeOH}$ & 0.244 & 0.148 & $b$ & 0.154 & $b$ & 0.035 & - & - \\
\hline $\mathrm{Ni} / \mathrm{EtOH}$ & & 0.164 & $b$ & 0.087 & $b$ & 0.029 & - & - \\
\hline
\end{tabular}

${ }^{a} k^{\prime}(\mathrm{mol} \mathrm{h})^{-1}$ is calculated from $\mathrm{Si}-\mathrm{OCH}_{2} \mathrm{CH}_{3}$ and $k^{\prime \prime}$ is calculated from $\mathrm{H}_{2} \mathrm{O}$. ${ }^{b}$ The reaction is too fast to be followed. 
in the condensation step. Hence, if a condensation occurs simultaneously with the hydrolysis the value of $k^{\mathrm{II}}$ should always be less than $k^{\mathrm{I}}$. An inspection of the values in Tables 1 and 2 verifies this, for both the TMOS and TEOS systems.

The tables also reveal the influence of different metal ions and solvents on the reaction rates. For the reactions between TMOS and $\mathrm{Ca}\left(\mathrm{NO}_{3}\right)_{2} \cdot 4 \mathrm{H}_{2} \mathrm{O}$ the solvent, ethanol or methanol seems to have a rather small impact on the rate of hydrolysis, with a slight preference for ethanol. However, when the same reaction is investigated for TEOS, methanol as the reaction media now gives a faster reaction. In the case of reactions between $\mathrm{Ni}\left(\mathrm{NO}_{3}\right)_{2} \cdot 6 \mathrm{H}_{2} \mathrm{O}$ and TMOS there is an obvious advantage to perform the reaction in ethanol as compared to methanol. The corresponding reactions with TEOS are too fast to be experimentally followed. When comparing the rate of hydrolysis for $\mathrm{Ca}$ and $\mathrm{Ni}$ it is clear that all reactions will proceed faster in the $\mathrm{Ni}$ system. The number of hydration waters, i.e. six in the nickel system and four in the calcium system, plays a role in the kinetics.

In a series of articles Friberg et al. ${ }^{8,9,12}$ have investigated reactions between tetraethoxysilane and different hydrated metal salts in ethanol or methanol without any added water. The kinetics were followed by ${ }^{29} \mathrm{Si} \mathrm{NMR}$. In the first work the reaction between TEOS and $\mathrm{Ca}\left(\mathrm{NO}_{3}\right)_{2} \cdot 4 \mathrm{H}_{2} \mathrm{O}$ in ethanol was followed by NMR. ${ }^{8}$ The results revealed a distinct difference in reactivity between TEOS and the different amounts of water of hydration. The reaction between TEOS and the first hydration water was completed after $24 \mathrm{~h}$. With two or three water molecules 15 days were sufficient. With four waters 33 days were needed to make the reaction complete. The condensation giving rise to the final gelation was much shorter, i.e. in the range $2-4 \mathrm{~h}$. The reaction rate greatly increased when the temperature was raised to $60^{\circ} \mathrm{C}$. For the first three hydrate waters the hydrolysis was complete after $12 \mathrm{~h}$, while the fourth water needed $24 \mathrm{~h}$ to leave $\mathrm{SiO}_{2}$ as the only reactions product. The dehydrated salt dit not precipitate, but stayed colloidally dispersed in the silica matrix.

In the study of reactions between $\mathrm{Al}\left(\mathrm{NO}_{3}\right)_{3} \cdot 9 \mathrm{H}_{2} \mathrm{O}$ and TEOS in ethanol Friberg et al. ${ }^{12}$ found the reaction between the first water of hydration and TEOS to be very fast, i.e. ca. $30 \mathrm{~min}$ at room temperature. The reaction involving all nine waters was not complete within nine days. At $60^{\circ} \mathrm{C}$ the reaction was accelerated. The reaction with up to four waters of hydration was complete after $12 \mathrm{~h}$, while all nine $\mathrm{H}_{2} \mathrm{O}$ had been consumed after $50 \mathrm{~h}$.

A profound difference was seen in the reaction between $\mathrm{Ca}\left(\mathrm{NO}_{3}\right)_{2} \cdot 4 \mathrm{H}_{2} \mathrm{O}, \mathrm{Al}\left(\mathrm{NO}_{3}\right)_{3} \cdot 9 \mathrm{H}_{2} \mathrm{O}$ and TEOS. ${ }^{12}$ Basically the aluminium salt showed acidity which catalyzed the reaction more efficiently. On a molecular level dielectric measurements have revealed the salts to be in different states when dissolved in an alcohol. ${ }^{10}$ In alcohol solutions $\mathrm{Ca}\left(\mathrm{NO}_{3}\right)_{2} \cdot 4 \mathrm{H}_{2} \mathrm{O}$ always displayed a higher static permittivity and longer relaxation times than $\mathrm{Al}\left(\mathrm{NO}_{3}\right)_{3} \cdot 9 \mathrm{H}_{2} \mathrm{O}$ solutions. On the other hand the latter solutions showed a much higher conductivity, revealing a higher level of dissociation. The conclusion is that $\mathrm{Ca}\left(\mathrm{NO}_{3}\right)_{2} \cdot 4 \mathrm{H}_{2} \mathrm{O}$ will appear as an ion pair under these conditions, wile $\mathrm{Al}\left(\mathrm{NO}_{3}\right)_{3} \cdot 9 \mathrm{H}_{2} \mathrm{O}$ will be dissociated.

When discussing the mechanisms underlying the reactions between a metal alkoxide and a hydrated metal salt, two different approaches can be adopted. The first route would be that the water of hydration is released from the metal salt and dissolved into the reaction medium, which is an alcohol. The other route would be that essentially all waters of hydration would remain attached to the metal salt, and that this complex as a whole should participate in the reaction.

In the first case, in which water molecules are released to the alcohol medium, the reaction between TEOS (TMOS) would be reminiscent of bulk reactions between metal alkoxide and 'free' water at a certain $\mathrm{pH}$. Literature values given by different authors ${ }^{3-6}$ report values in the range $0.3-0.8 \mathrm{~L}(\mathrm{~mol} \mathrm{~h})^{-1}$. The highest ones reported are $>12 \mathrm{~L}(\mathrm{~mol} \mathrm{~h})^{-1.4}$ In Ref. 5 a value of $0.2 \mathrm{~L}(\mathrm{~mol} \mathrm{~h})^{-1}$ was established as the lower limit for the hydrolysis rate constant when based on second-order kinetics. When compared with these values the data in Tables 1 and 2 reveal some interesting features. For reactions with TMOS the hydrolysis in the calcium-based system shows values close to or below a value of $0.2 \mathrm{~L}(\mathrm{~mol} \mathrm{~h})^{-1}$. Only for the highest hydration water-to-TMOS ratio of 8 , does the hydrolysis rate approach values reported in the literature. For the Ni-based systems all rate constants fall in an interval reported in the literature. The trends are similar with respect to reactions with TEOS (Table 2). The conclusion to be drawn is that at the lowest ratios of hydration water to metal alkoxide the dissolution of hydration water into the alcohol media seems to be a less satisfactory reaction route, while at high ratios $(>4)$ the values of the rate of hydrolysis can be compared with normal sol-gel systems with free water in the reaction media. The state of the hydrated metal complex in the alcohol will thus be of crucial importance as a catalyst of the hydrolysis reaction. The simplest approach to give a qualitative explanation to this behaviour is to measure the $\mathrm{pH}$ dependence of the alcohol/hydrated metal nitrate solutions. In our case 45 wt. $\%$ of $\mathrm{Ca}\left(\mathrm{NO}_{3}\right)_{2} \cdot 4 \mathrm{H}_{2} \mathrm{O}$ dissolved in the alcohols gave a $\mathrm{pH}$ of approximately 5, while $\mathrm{Ni}\left(\mathrm{NO}_{3}\right)_{2} \cdot 6 \mathrm{H}_{2} \mathrm{O}$ gave a $\mathrm{pH}$ of 3 . The lower $\mathrm{pH}$ of the $\mathrm{Ni}$ system will obviously promote the hydrolysis more efficiently, ${ }^{13}$ a fact confirmed by the values in Tables 1 and 2.

When comparing our results with that of Friberg et al., ${ }^{8-10}$ it is tempting to ascribe the higher activity of the $\mathrm{Ni}$-aqua complex to a higher degree of dissociation. In this way both the higher reactivity and lower $\mathrm{pH}$ can be explained.

In the reaction between TMOS and $\mathrm{Ni}\left(\mathrm{NO}_{3}\right)_{2} \cdot 6 \mathrm{H}_{2} \mathrm{O}$ it was possible to calculate condensation rates from $\mathrm{Si}-$ $\mathrm{OH}$. It was found that the condensation was about four times faster with a water-to-TMOS ratio of 4 than 2 . The same trend was seen for both alcohols. 
Acknowledgements. M. H. S. acknowledges the Research Council of Norway (NFR) for a research grant (Dr. Scient).

\section{References}

1. Brinker, C. J. and Scherer, G. W. Sol-Gel Science, Academic Press, New York 1990.

2. Klein, L. C., Ed., Sol-Gel Technology for Thin Films, Performs, Electronics and Specialty Forms, Noyes Publications, New Jersey 1988.

3. Aelion, R., Loebel, A. and Eirich, F. J. Am. Chem. Soc. 72 (1950) 5705.

4. Assink, R. A. and Kay, B. D. J. Non-Cryst. Solids 107 (1988) 35 .

5. Pouxviel, J. C. and Boilot, J. P. J. Non-Cryst. Solids 94 (1987) 374
6. Yang, H., Ding, Z., Jiang, Z. and Xu, X. J. Non-Cryst. Solids 112 (1989) 449

7. Sanchez, J. and McCormick, A. J. Phys. Chem. 96 (1992) 8973.

8. Friberg, S. E., Amran, A. and Sjöblom, J. J. Disp. Sci. Technol. 15 (1994) 621.

9. Friberg, S. E., Yang, J., Amran, A., Sjöblom, J. and Farrington, G. J. Phys. Chem. 98 (1994) 13528.

10. Gestblom, B., Mehrotra, S. C. and Sjöblom, J. J. Solution Chem. 15 (1986) 55.

11. Assink, R. A. and Kay, B. D. J. Non-Cryst. Solids 99 (1988) 359.

12. Sjöblom, J., Friberg, S. E. and Amran, A. J. Disp. Sci. Technol. 16 (1995) 31

13. Cihlár, J. Colloids Surf 70 (1993) 239.

Received February 21, 1995. 